Original Article

\title{
CO-CRYSTALS OF ACTIVE PHARMACEUTICAL INGREDIENT-IBUPROFEN LYSINE
}

\author{
ALPANA KULKARNI*, RITESH BACHHAV, VISHAL HOL, SWAPNIL SHETE
}

Department of Pharmaceutics, MAEER'S Maharashtra Institute of Pharmacy, S. No. 124, MIT Campus, Paud Road, Kothrud, Pune 411038, Maharashtra, India

Email: alpana.kulkarni@mippune.edu.in

Received: 12 Dec 2019, Revised and Accepted: 28 Feb 2020

\section{ABSTRACT}

Objective: Co-crystal is defined as a crystalline complex of two or more neutral molecules bound together primarily by hydrogen bonding or other non-covalent interactions. The pharmaceutical co-crystal involves crystal lattice arrangement between an Active Pharmaceutical Ingredient (API) with another pharmaceutically acceptable molecule. Co-crystals of API are preferred since they depict improved solubility, dissolution, stability, compressibility in comparison with API. Ibuprofen lysine (IL), frequently used analgesic and the anti-inflammatory drug has poor aqueous solubility and compressibility. This work shows the feasibility and optimal conditions for the preparation of co-crystals of ibuprofen lysine using Polyvinylpyrrolidone K25 (PK 25) and Polyvinylpyrrolidone K30 (PK 30) as co-formers.

Methods: In this study, we prepared and studied the solubility, drug content, flow properties, physical stability of novel co-crystal, consisting of IL and PK 25/PK 30. The co-crystal IL: PK 30 (at a molar ratio of 0.29:0.5) and IL: PK 25 (at a molar ratio of 0.58:1) were characterized by X-ray analysis, infrared spectroscopy and thermal analysis. Furthermore, the tablet formulations of the co-crystals were subjected to in vitro dissolution and in vivo analgesic activity, with the goal of comparing the co-crystals with IL and the marketed tablet of ibuprofen (Brufenß) respectively.

Results: The IL: PK co-crystals demonstrated superior solubility and the dissolution properties over IL. The compression properties of the cocrystals were similar to IL. The co-crystals exhibited higher analgesic activity than the marketed tablet.

Conclusion: The results indicated the use of PK 25 and PK 30 as safe and promising co-crystal formers.

Keywords: Ibuprofen, Co-crystal, Polyvinylpyrrolidone, Solubility, Non-covalent, Analgesic

(C) 2020 The Authors. Published by Innovare Academic Sciences Pvt Ltd. This is an open access article under the CC BY license (http://creativecommons.org/licenses/by/4.0/) DOI: http://dx.doi.org/10.22159/ijap.2020v12i3.36463. Journal homepage: https://innovareacademics.in/journals/index.php/ijap

\section{INTRODUCTION}

Ibuprofen is BCS class II drug having high permeability and low solubility. (Dose is $600 \mathrm{mg}$, dose no is 164.38) It is remembered for the WHO Model List of Essential Medicines of the most significant drugs required in a fundamental wellbeing framework [1]. Ibuprofen (pKa esteem 4.91) has a poor and exceptionally $\mathrm{pH}$-subordinate solvency [2]. Ibuprofen dissolves readily above $\mathrm{pH} 6.5$ and is quickly absorbed from the small intestine in comparison with the stomach. The blood level reaches to a maximum of 1.5 to $2 \mathrm{~h}$ after ingestion. It indicates delayed or incomplete absorption and is attributed to the $\mathrm{pH}$ conditions of the small intestine [1]. Designing of ibuprofen formulation is challenging since it has $\mathrm{pH}$-dependent solubility and permeability [3]. The aqueous solubility of ibuprofen salts is higher than that of the drug substance. The variation in bioavailability of ibuprofen is resolved by using ibuprofen salts, in particular, ibuprofen lysinate, ibuprofen arginate, ibuprofen sodium [1].

Crystal engineering is based upon complex formation between the molecules through supramolecular synthons leading to co-crystals, formation [4]. Zaworotko has characterized a co-crystal as a multicomponent crystal, formed between two solids, in which one component is molecular and structures a supramolecular synthon with the other component. This incorporates the atomic adducts of particles. [5, 6]. Crystal engineering is based on non-covalent interactions between atoms/molecules and is useful in designing and synthesis of solid-state structures such as salts or polymorphs. Co-crystallization is an ongoing methodology, utilized in pharmaceutical sciences, for designing the APIs having attractive physical and substance properties [7]. The pharmaceutical industry is in search of novel robust, reliable and safe supramolecular synthon.

Literature search reveals the co-crystals of ibuprofen with nicotinamide [8], urea, succinic acid, salicylic acid, 3-and 4aminobenzoic acid, cinnamic acid, citric acid, oxalic acid, benzoic acid [3]. Significantly less research has been done on the synthesis of co-crystals of salts of ibuprofen.
Polyvinylpyrrolidone is a water-soluble tertiary amide polymer of (N-vinyl-2-pyrrolidone) and is reported as a proton acceptor [9]. Polyvinylpyrrolidone is used as a carrier (in solid dispersion), dispersing agent, suspending agent, film former (in eye drops), binder, diluent, coating agent (in tablets), blood volume expander. However, it has received little attention as the co-former in the formation of co-crystals [10-11].

The aim of the study was to prepare the co-crystals of salt of Active Pharmaceutical Ingredient (API) with polymer as the co-former and to evaluate the solubility and the compressibility of the co-crystals. In this study, the salt ibuprofen lysine (IL), was used as the host molecule with the co-crystal formers namely, Polyvinylpyrrolidone K25 and Polyvinylpyrrolidone K30 (PK 25 and PK 30) possessing a pyrrolidine ring and an amino $\left(\mathrm{NH}_{2}\right)$ group.

\section{MATERIALS AND METHODS}

\section{Materials}

Ibuprofen lysine IP was generously gifted by Mylan Laboratories, Malegaon, Sinnar, Maharashtra. Povidone (Polyvivylpyrrolidone) K25 USP and Povidone K30 USP were gifted by Getz Pharma Research Pvt Ltd, Addl Ambernath, Thane. Brufen® ${ }^{\circledR}$ tablets (Abott India Ltd, Verna, Goa) were procured from the local market. Talc IP, magnesium stearate IP, microcrystalline cellulose IP was purchased from New Neeta Chemicals, Chinchwad, Pune. Absolute ethanol AR was used as received from Rathod Suppliers, Pune.

\section{Screening of co-crystals by the solvent evaporation method}

Accurately weighed ibuprofen lysine was dissolved in ethanol (5 $\mathrm{ml}$ ). Polyvinylpyrrolidone K-25/polyvinylpyrrolidone K-30 was dissolved in $5 \mathrm{ml}$ of ethanol. (table 1) The coformer solution was added to the ibuprofen lysine solution gradually with continuous stirring at $2000 \mathrm{rpm}$ for $20 \mathrm{~min}$ at $35{ }^{\circ} \mathrm{C}$. The stirring was continued till complete dissolution. The container was left uncapped for gradual evaporation of the solvent at $35^{\circ} \mathrm{C}$ for $1 \mathrm{w}$. White-colored co-crystals were obtained and triturated gently in 
the pestle mortar to a fine powder before analyses. Each formulation was prepared in three sets.

\section{Screening of co-crystals by liquid assisted grinding method}

Accurately weighed ibuprofen lysine was mixed with polyvinylpyrrolidone $\mathrm{K}-25 /$ polyvinylpyrrolidone $\mathrm{K}-30$ in the pestle mortar in the absence of any solvent for 20 min. (table 1) initial mixing was followed by the dropwise addition of ethanol $(5 \mathrm{ml})$ and continuous trituration for $20 \mathrm{~min}$. The container was left uncapped for gradual evaporation of the solvent at $35^{\circ} \mathrm{C}$ for $1 \mathrm{w}$. White-colored co-crystals were obtained and triturated gently in the pestle mortar to a fine powder before analyses. Each formulation was prepared in three sets.

Table 1: Screening of co-crystals of ibuprofen lysine

\begin{tabular}{|c|c|c|c|c|c|c|}
\hline $\begin{array}{l}\text { S. } \\
\text { No. }\end{array}$ & Ingredients & $\begin{array}{l}\text { Stoichiometric ratio of I: } \\
\text { co-former ( } \mathrm{mmol})\end{array}$ & $\begin{array}{l}\text { Weight of } \\
\text { drug (g) }\end{array}$ & $\begin{array}{l}\text { Weight of co- } \\
\text { former }(\mathrm{g})\end{array}$ & $\begin{array}{l}\text { Formulation code-liquid } \\
\text { assisted grinding }\end{array}$ & $\begin{array}{l}\text { Formulation code- } \\
\text { solvent evaporation }\end{array}$ \\
\hline 1 & $\mathrm{IL}+\mathrm{K}-25$ & $1.16: 2$ & 0.8241 & 0.0485 & A1 & B1 \\
\hline 2 & $\mathrm{IL}+\mathrm{K}-30$ & 1.16: 2 & 0.8241 & 0.0598 & $\mathrm{~A} 2$ & B2 \\
\hline 3 & $\mathrm{IL}+\mathrm{K}-25$ & 1.16: 1 & 0.8241 & 0.0242 & A3 & B3 \\
\hline 4 & $\mathrm{IL}+\mathrm{K}-30$ & 1.16: 1 & 0.8241 & 0.0299 & A4 & B4 \\
\hline 5 & $\mathrm{IL}+\mathrm{K}-25$ & 0.58: 1 & 0.4120 & 0.0242 & A5 & B5 \\
\hline 6 & $\mathrm{IL}+\mathrm{K}-30$ & $0.58: 1$ & 0.4120 & 0.0299 & A6 & B6 \\
\hline 7 & $\mathrm{IL}+\mathrm{K}-25$ & $0.29: 0.5$ & 0.2060 & 0.0121 & A7 & B7 \\
\hline 8 & $\mathrm{IL}+\mathrm{K}-30$ & $0.29: 0.5$ & 0.2060 & 0.0149 & A8 & B8 \\
\hline
\end{tabular}

Where, IL-Ibuprofen lysine; K-25-polyvivylpyrrolidone K-25; K-30-polyvivylpyrrolidone K-30

\section{Evaluation of co-crystals of ibuprofen lysine}

The $\%$ yield, the solubility and the drug content of the co-crystals were determined.

The $\%$ yield of the co-crystal formulations was determined as follows.

$$
\% \text { yield }=\frac{\text { weight of } \mathrm{co}-\text { crystal formulation }}{\text { weight of drug }+ \text { co }- \text { former }} \times 100
$$

For determination of solubility, excess of ibuprofen lysine/cocrystals was added to distilled water $(10 \mathrm{ml})$. The drug content was evaluated by adding co-crystal formulation (equivalent to $30 \mathrm{mg}$ of drug substance) to ethanol $(10 \mathrm{ml})$. The suspension was agitated on a magnetic stirrer at $100 \pm 10 \mathrm{rpm}$ for $24 \mathrm{~h}$ at $37 \pm 0.5^{\circ} \mathrm{C}$ and filtered through Whatman filter paper no. 41. The absorbance was measured at $221 \mathrm{~nm}$ with UV Spectrophotometer (Varian Cary 100 Scan). The UV spectrophotometric method was developed and validated in our laboratory. Results are not disclosed. Drug content was calculated as follows.

$$
\% \text { drug content }=\frac{\text { calcualted drug content }}{\text { Theoretical drug content }} \times 100
$$

The angle of repose, bulk and tapped density, Hausner's ratio, Compressibility Index of the co-crystals A5 and B8 were determined and compared with ibuprofen lysine. The structure of the co-crystals A5 and B8 were identified by Fourier Transformer Infrared spectroscopy, Differential Scanning Calorimetry and Powder X-Ray Diffractometry. The surface characteristics of IL, PK 25, PK 30, cocrystals A5 and B8 were studied with Motic microscope (Motic BA 210). The samples (10 mg) were mounted on a glass slide and observed under the microscope.

\section{Stability study}

The co-crystals A5 and B8 were wrapped in double layers of aluminum foil and were stored at $40 \pm 2{ }^{\circ} \mathrm{C}$ and $75 \pm 5 \%$ relative humidity in a stability chamber (Thermo Labs) [12]. The physical appearance, the drug content and the solubility of the co-crystals were examined at pre-determined time intervals for $3 \mathrm{mo}$.

\section{Preparation of tablet formulations of co-crystals of ibuprofen lysine}

The tablet formulations consisting of ibuprofen lysine: polyvinylpyrrolidone K25/K30 co-crystals or ibuprofen lysine alone were prepared. Direct compression was employed for preparing three tablet formulations, namely, ibuprofen lysine (tablet T1), ibuprofen lysine: PK 25 co-crystal A5 (tablet T2) and ibuprofen lysine: PK 30 co-crystal B8 (tablet T3). Following excipients were incorporated: Avicel pH 102 (microcrystalline cellulose) (112.0 mg), magnesium stearate $(1.25 \mathrm{mg})$ and talc $(8.75 \mathrm{mg})$ per tablet with co-crystal A5 (300 mg equivalent to $228 \mathrm{mg}$ of ibuprofen lysine) and co-crystal B8 (228 mg equivalent to $228 \mathrm{mg}$ of ibuprofen lysine), respectively. A tablet press instrument (Mini Press-II 'D' Rimek) was used for this purpose (table 2).

\begin{tabular}{|c|c|c|c|c|c|}
\hline S. No. & Ingredient & Purpose & $\begin{array}{l}\text { Quantity/ Tablet } \\
\text { T1 (mg) }\end{array}$ & $\begin{array}{l}\text { Quantity/tablet T2 } \\
\text { (mg) }\end{array}$ & $\begin{array}{l}\text { Quantity/tablet } \\
\text { T3 (mg) }\end{array}$ \\
\hline 1 & Ibuprofen lysine & Drug substance & 228 & - & - \\
\hline 2 & Co-crystal formulation A5 & Drug substance & - & 300 & - \\
\hline 3 & Co-crystal formulation B8 & Drug substance & - & - & 228 \\
\hline 4 & Talc & Glidant & 8.75 & 8.75 & 8.75 \\
\hline 5 & Microcrystalline cellulose & Binder and Diluent & 112 & 40 & 112 \\
\hline 6 & Magnesium stearate & Lubricant/anti-adherent & 1.25 & 1.25 & 1.25 \\
\hline
\end{tabular}

Table 2: Formulation of tablets of co-crystals of ibuprofen lysine

\section{Evaluation of tablet formulations of co-crystals of ibuprofen lysine}

The appearance, dimensions [13], weight variation [13], hardness [14], friability [14], disintegration time [13] of tablets T1, T2, T3 were recorded.

\section{In vitro dissolution}

In vitro dissolution of three tablets, containing co-crystal A5 or co-crystal B8 or ibuprofen lysine was performed in paddle-type USP Dissolution Test Apparatus (Electro Lab, TDL-08L) at $37 \pm 0.5{ }^{\circ} \mathrm{C}$ and $50 \mathrm{rpm}$. The dissolution medium was distilled water $(900 \mathrm{ml})$. The samples were collected at $0,10,15,20,30,45$ and 60 min. An equal volume of fresh dissolution medium was replaced to maintain the volume of the dissolution medium. The absorbance of the withdrawn samples was measured at $221 \mathrm{~nm}$ and the drug release was determined.

In vivo study of tablet formulations of co-crystals of ibuprofen lysine

The analgesic activity of the tablet formulations of the co-crystals was determined by the hot plate method. Mature albino Swiss mice (5- 
$30 \mathrm{~g}$ ) of both sexes were housed under standard room temperature and relative humidity $(70-80 \%)$. The animals were fed with standard commercial diet and water ad libitum. The animals were fasted for $12 \mathrm{~h}$ prior to the experiment with water given ad libitum and weighed. All procedures were reviewed and approved by the Ethics Committee of (941/Po/c/06/CPCSEA; 30/06/2009). The mice were randomly assigned to five groups of six animals each. The first, second and third groups received T2, T3 and T1 tablets, respectively. The tablets were added to purified water, filtered and the samples (equivalent to a dose of $6 \mathrm{mg}$ of ibuprofen $/ \mathrm{kg}$ ) were administered orally to the animals using an oral gavage needle. The fourth and the fifth groups served as positive control and negative control receiving Brufen ${ }^{\circledR}$ tablet equivalent to a dose of $6 \mathrm{mg}$ of ibuprofen $/ \mathrm{kg}$ ) and normal saline $(10 \mathrm{ml} / \mathrm{kg})$. All treatments were administered orally.

The animal was placed on a hot plate (temperature $55^{\circ} \mathrm{C}$ ). The latency period or reaction time (s) was determined as the time taken by the animal to react to the thermal pain by jumping or licking its paws. The reaction time was recorded before (at $0 \mathrm{~min}$ ) and at 15 , $30,45,60$ and $120 \mathrm{~min}$ after the administration of the tablets. The maximum reaction time was fixed at $15 \mathrm{~s}$ to prevent any injury to the paw tissues. If the reaction time exceeded $15 \mathrm{~s}$, it was considered as maximum analgesia. The index of analgesia or $\%$ increase in reaction time was determined at each time interval. Data were presented as mean \pm standard error mean (SEM).

\section{RESULTS AND DISCUSSION}

\section{Screening of co-crystals of ibuprofen lysine}

The co-formers, namely, 4-hydroxybenzoic acid [3], nicotinamide $[18,19]$ and 2-aminopyrimidine $[20]$ were used for screening the cocrystals of ibuprofen. In the reported crystal structures of ibuprofen, the molecules are linked through hydrogen-bonded supramolecular synthons such as acid-amide, amide dimer, acid-aromatic nitrogen, $\mathrm{NH}_{2}$ dimer [21] and acid dimer. Polyvinylpyrrolidone derivatives are used as a disintegrant, tablet binder, dissolution enhancer and suspending agent. However, co-crystals of APIs with Polyvinylpyrrolidone are not reported. We have hypothesized that the soluble Polyvinylpyrrolidone and API might form heterosynthons, which might induce co-crystallization.

Fig. 1, drawn with Chem Draw software, shows the proposed hydrogen bonding between the guest and the host compounds. The $\mathrm{pK}_{\mathrm{a}}$ of ethanol and water is 15.9 and 15.7, respectively. Ethanol depicts the loss of proton from hydroxyl group [22]. Hence we hypothesize that ibuprofen lysine undergoes dissociation in ethanolic solution and forms ibuprofen and lysine. Ibuprofen donates 1 hydrogen and accepts 2 hydrogen. The hydrogen donor count and the hydrogen acceptor count of PK is 0 and 1 , respectively. The-H from carboxylic acid functional group $(-\mathrm{COOH})$ of ibuprofen has a potential of forming hydrogen bond with the carbonyl group ($\mathrm{C}=0$ ) of PK-25 and PK-30. Ibuprofen acts as the proton donor, whereas $\mathrm{PK}$ acts as the proton acceptor. We propose that ibuprofen is linked with PK through hydrogen-bonded supramolecular synthons, namely, acid-carbonyl (an interaction between the carbonyl group $(-\mathrm{C}=\mathrm{O})$ of $\mathrm{PK}$ and the hydrogen $(-\mathrm{H})$ of the carboxylic acid functional group of ibuprofen).

Crystallization strategy and conditions for screening are commonly founded on one of two techniques. In system 1 , solvents or dissolvable blends of solutions, with comparable solubility for reactants, are chosen and stoichiometric concentrations of reactants are utilized. In methodology 2, solvents or dissolvable blends of solvents, depicting different solubility for reactants, are chosen, and nonstoichiometric reactant arrangement is utilized [23]. In the present work, system 2 was chosen. The primary concern, in the selection of the solvent, was the solvent's ability to create adequate super saturation for the co-crystal nucleation while evading supersaturation for the reactants. Crystallization by evaporation of non-stoichiometric solutions depended on system 2 .
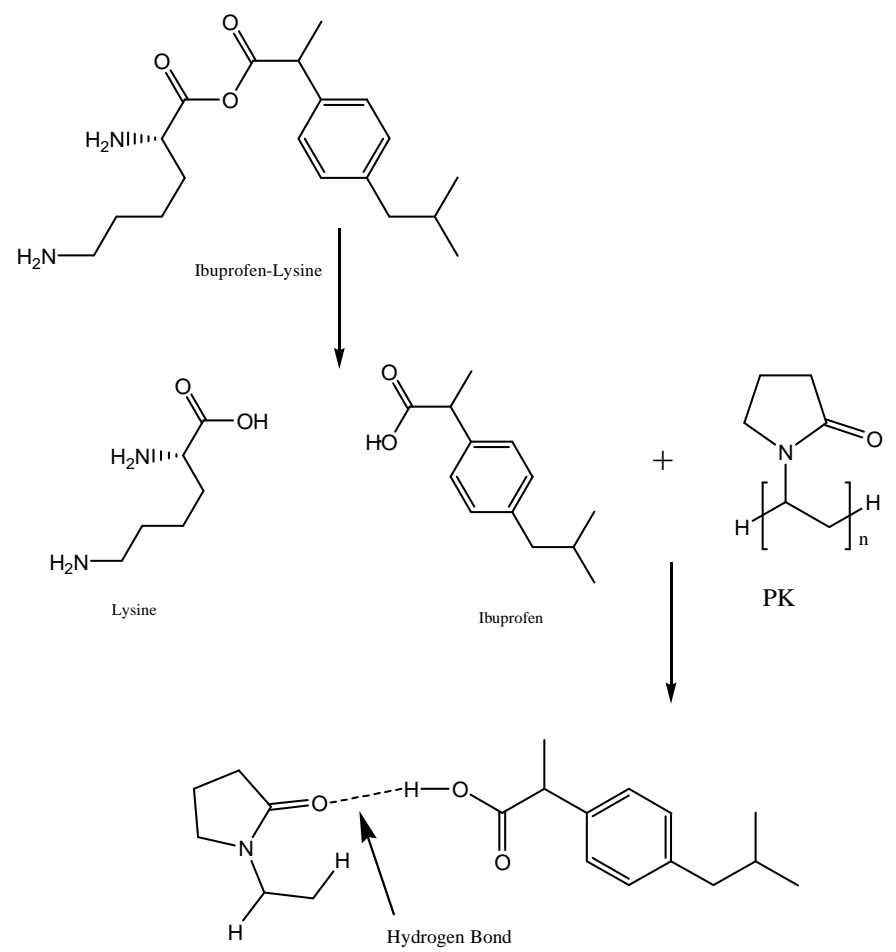

Fig. 1: Formation of hydrogen bond in co-crystal

The solid forms were set up by two strategies Liquid Assisted grinding (LAG) and solvent evaporation (SE). The co-crystal components are dissolved in a solvent and the solvent is evaporated gradually in solvent evaporation. However, on a modern scale, SE is less preferred since it requires more time for evaporation and leads to environmental pollution. A "green" approach is to add a solvent to the mixture and to grind the components together in the presence of the solvent (LAG). LAG experiments require less solvent, less time consuming, and may produce the resultant co-crystal and its polymorphs [8]. Two screening methods led to the discovery of sixteen solid forms containing ibuprofen lysine. Sixteen co-crystals were prepared on a scale adequate for determination of solubility, 
drug content and flow properties. The \% yield, solubility, drug content and flow properties of the solid forms were compared and the hits were decided.

\section{Evaluation of co-crystals of ibuprofen lysine Percentage (\%) yield}

For all the co-crystals, the collected powders were white and fairly free-flowing. The percentage yield of co-crystals obtained by LAG was higher than by SE. (table 2 and 3) the lower yield in case of SE was attributed to the process loss.

\section{Drug content and solubility}

The solubility of ibuprofen lysine in distilled water was 5.419 $\mu \mathrm{g} / \mathrm{ml}$. Both the co-formers and the crystallization techniques improved the aqueous solubility of ibuprofen lysine. (table 3 and 4) The \% drug content and solubility of co-crystals, consisting of PK-30 as the co-former and prepared by SE, were better than those of the co-crystals consisting of PK-25 and prepared by LAG. The co-crystal B8 demonstrated higher drug dissolution than the co-crystal A5.

Table 3: Characterization of co-crystals prepared by LAG method

\begin{tabular}{lllll}
\hline S. No. & Formulation code & Yield (\%) & Drug content (\%) & Solubility $(\boldsymbol{\mu g} / \mathbf{m l})$ \\
\hline 1 & A1 & $84.04 \pm 13.88$ & $46.31 \pm 14.95$ & $41.35 \pm 7.79$ \\
2 & A2 & $78.09 \pm 13.89$ & $50.89 \pm 11.49$ & $43.69 \pm 10.58$ \\
3 & A3 & $83.36 \pm 12.61$ & $55.11 \pm 12.98$ & $43.04 \pm 15.49$ \\
4 & A4 & $82.80 \pm 13.39$ & $49.95 \pm 9.67$ & $48.64 \pm 12.94$ \\
5 & A5 & $\mathbf{9 1 . 3 3 \pm 5 . 9 9}$ & $44.40 \pm 0.9205$ & $\mathbf{4 2 . 4 3 \pm 1 2 . 4 6}$ \\
6 & A6 & $68.90 \pm 11.84$ & $65.54 \pm 8.97$ & $34.96 \pm 8.37$ \\
7 & A7 & $65.06 \pm 35.57$ & $79.69 \pm 20.37$ & $28.14 \pm 2.98$ \\
8 & A8 & $68.39 \pm 30.90$ & $76.26 \quad \pm 13.07$ & 30.54 \\
\hline
\end{tabular}

Each observation is an average of three experiments $(n=3) \pm S D$

Table 4: Characterization of co-crystals prepared by SE method

\begin{tabular}{lllll}
\hline S. No. & Formulation code & Yield (\%) & Drug content (\%) & Solubility ( $\boldsymbol{\mu g} / \mathbf{m l})$ \\
\hline 1 & B1 & $64.81 \pm 12.42$ & $57.85 \pm 7.79$ & $49.73 \pm 5.43$ \\
2 & B2 & $63.61 \pm 18.48$ & $49.33 \pm 3.22$ & $50.55 \pm 16.91$ \\
3 & B3 & $73.55 \pm 11.88$ & $60.31 \pm 2.78$ & $38.99 \pm 7.25$ \\
4 & B4 & $78.80 \pm 18.76$ & $49.38 \pm 5.21$ & $40.73 \pm 6.17$ \\
5 & B5 & $61.76 \pm 17.31$ & $60.92 \pm 16.03$ & $32.7 \pm 8.82$ \\
6 & B6 & $66.07 \pm 12.36$ & $54.87 \pm 5.35$ & $43.21 \pm 7.09$ \\
7 & B7 & $50.48 \pm 15.88$ & $70.93 \pm 7.33$ & $43.84 \pm 12.33$ \\
8 & B8 & $72.92 \pm 4.84$ & $87.08 \pm 19.26$ & $53.52 \pm 4.39$ \\
\hline
\end{tabular}

Each observation is an average of three experiments $(n=3) \pm S D$

\section{Flow properties}

The co-crystals, A5 and B8 revealed good flow properties. However, the compression properties of co-crystals were not improved. The compression properties of B8 were slightly improved than ibuprofen lysine (table 5).

\section{Stability study}

The stability of the co-crystals A5 and B8 includes determination of the solubility and the drug content of the co-crystals samples at different time intervals and comparison with the previous results.
The results confirmed the stability of A5 and B8 for 3 mo (table 6). Any significant change in the physical appearance of the co-crystals was not observed.

\section{FTIR spectroscopy}

Fig. 2, 3 and 4 show the IR spectra of ibuprofen lysine, the cocrystals A5 and B8, respectively. The IR spectra of the polymers, namely, PK 25 and PK 30 are not shown. A listing of the most characteristic IR bands of the co-crystals examined herein is given in table 7 and 8, together with the data for ibuprofen lysine and the corresponding co-crystal formers.

Table 5: Flow properties of co-crystals

\begin{tabular}{|c|c|c|c|c|c|c|}
\hline S. No. & Ingredient & Angle of repose $\left({ }^{\circ}\right)$ & Tapped density & Bulk density & Carr's index (\%) & Hausner's ratio \\
\hline 1 & Ibuprofen lysine & 31.21 & 0.72 & 0.350 & 51.38 & 2.05 \\
\hline 2 & Co-crystals A5 & 26.13 & 0.73 & 0.336 & 53.97 & 2.17 \\
\hline 3 & Co-crystals B8 & 26.28 & 0.71 & 0.368 & 48.16 & 1.93 \\
\hline
\end{tabular}

Table 6: Stability study of co-crystals

\begin{tabular}{lllll}
\hline Days & Co-crystal A5 & & Co-crystal B8 \\
\cline { 2 - 5 } & Drug content (\%) & Solubility $(\boldsymbol{\mu g} / \mathbf{m l})$ & Drug content $(\%)$ \\
\hline 0 & 44.4 & 42.43 & 87.08 & Solubility $(\boldsymbol{\mu g} / \mathbf{m l})$ \\
14 & 44.38 & 42.40 & 87.05 & 53.52 \\
21 & 44.35 & 42.38 & 87.02 & 53.50 \\
28 & 44.33 & 42.35 & 87.00 & 53.47 \\
43 & 44.30 & 42.33 & 86.98 & 53.46 \\
58 & 44.28 & 42.37 & 86.95 & 53.40 \\
73 & 44.34 & 42.31 & 87.03 & 53.38 \\
88 & 44.37 & 42.34 & 53.45 \\
\hline
\end{tabular}

The co-crystals A5 and B 8 were subjected to FTIR spectroscopy, DSC and XPRD. 
Table 7: Relevant bands in IR spectra of co-crystal A5, ibuprofen lysine, Co-former

\begin{tabular}{lllll}
\hline S. No. & Functional groups & Standard value (cm-1) & Observed value (cm-1) & $\begin{array}{l}\text { Similar to } \\
\text { Ibuprofen lysine PK 25 }\end{array}$ \\
\hline 1 & O-H stretching & $3600-3200$ & 3405 \\
2 & C=O stretching & $1730-1700$ & 162.92 & 1624 \\
3 & C-H stretching of the methyl group & $3000-2850$ & 2907.16 & 2921 \\
4 & C-N stretching & $1300-1000$ & 1278.57 & 1291 \\
5 & CH bending & 1465 & 1449.24 & 1435 \\
6 & C=C stretching aromatic ring & $1600-1500$ & 1628 & 1561 \\
7 & O-H bending & 920 & 913.129 & \\
\hline
\end{tabular}

Table 8: Relevant bands in IR spectra of co-crystal B8, ibuprofen lysine, Co-former

\begin{tabular}{lllll}
\hline S. No. & Functional groups & Standard value $\left.\mathbf{( c m}^{-1}\right)$ & Observed value $\left(\mathbf{c m}^{-1}\right)$ & Similar to Ibuprofen lysine PK 30 \\
\hline 1 & O-H stretching & $3600-3200$ & 3456.78 & 3452.92 \\
2 & C=O stretching & $1730-1700$ & 1626.66 & 1626.661624 .73 \\
3 & C-H stretching of methyl group & $3000-2850$ & 2925.48 & 2838.62 \\
4 & C-N stretching & $1300-1000$ & 1224.58 & 1289.18 \\
5 & CH2 bending & 1465 & 1447.31 & 1432 \\
6 & C=C stretching aromatic ring & $1660-1600$ & 1583.27 & 1561.091587 .13 \\
7 & O-H bending & 920 & 914.093 & \\
\hline
\end{tabular}

The resulting spectra of both the co-crystals were different from the IR spectra of ibuprofen lysine. The broad bands, in the region of 2500-3500 $\mathrm{cm}$, indicated hydrogen bond formation between ibuprofen and PK. The co-crystal spectrum was different from the ibuprofen spectrum in two specific regions: in between $900-1500 \mathrm{~cm}^{-1}$, characteristic of $\mathrm{CH}_{2}$ and $\mathrm{CH}_{3}$ wags, and in between $820-850 \mathrm{~cm}^{-1}$ [19]. The co-crystals A5 and B8 revealed numerous peaks in the region $900-1500 \mathrm{~cm}^{-1}$ confirming the presence of ibuprofen. The intensity of the peaks in between 820-850 $\mathrm{cm}^{-1}$ was reduced in the co-crystal spectrum [19].

The co-crystals A5 and B8 revealed two characteristic bands, in the region $1730-1700 \mathrm{~cm}^{-1}$ for the $\mathrm{C}=0$ stretching and in the region of
1660-1600 $\mathrm{cm}^{-1}$ for the $\mathrm{C}=\mathrm{C}$ stretching of the aromatic ring. It indicated the presence of ibuprofen in the solid phases of A5 and B8. However, the spectra of the co-crystals depicted changes in the frequency and bandwidth of interacting groups [18]. It was attributed to the blending of ibuprofen with PK and the subsequent changes in the oscillating dipoles. These peaks indicated the interaction between ibuprofen and PK and the formation of crystal lattice arrangement to some extent. It was predicted that the crystal lattice arrangement was not completely formed. The inability of completion of crystal lattice rearrangement was due to inadequate drug: co-former stoichiometric ratio.

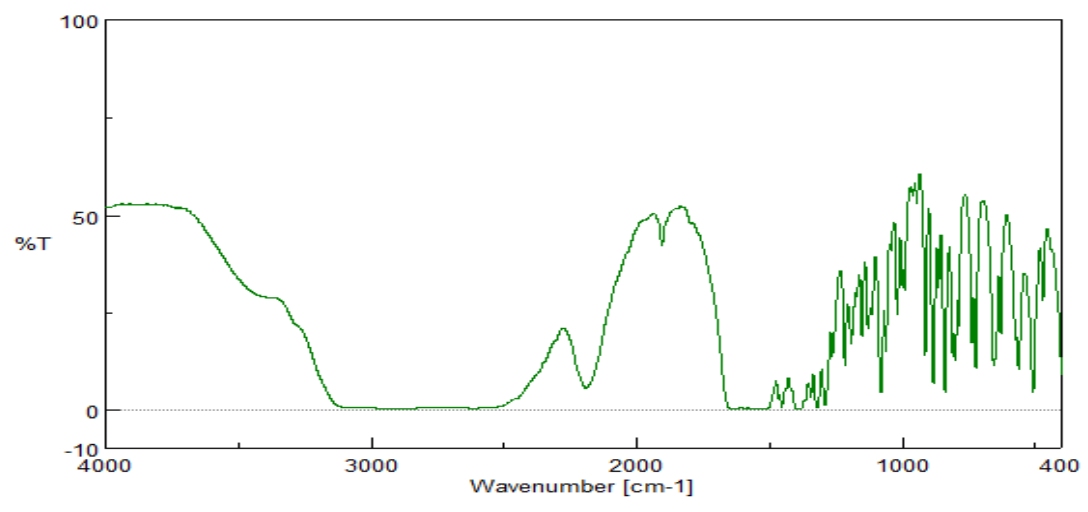

Fig. 2: Infra-red spectrum of ibuprofen lysine

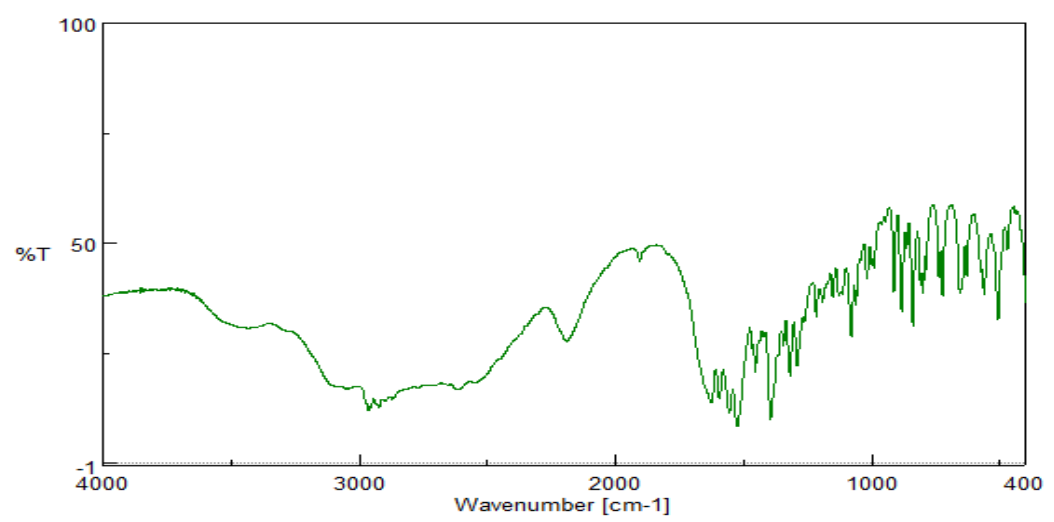

Fig. 3: IR spectrum of co-crystal A5 


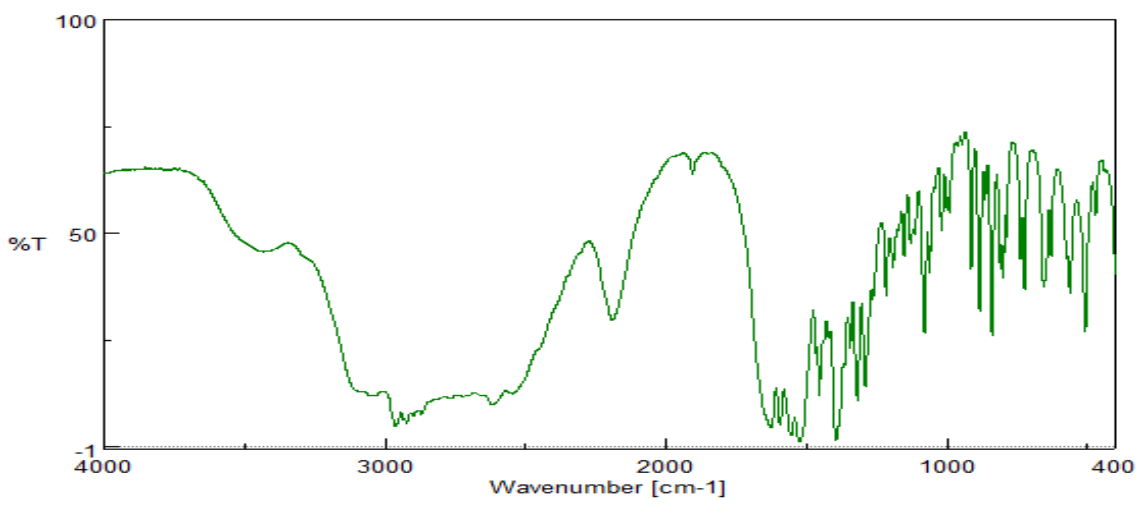

Fig. 4: IR spectrum of co-crystal B8

It was inferred that the salt was not formed in between ibuprofen and the co-formers since the IR band due to $\mathrm{C}=0$ stretching was observed at $1624 \mathrm{~cm}^{-1}$ and $1626 \mathrm{~cm}^{-1}$ respectively. The IR spectra of the cocrystals did not show a shift to lower wavenumbers in comparison with the API and the co-formers. It indicated the absence of a proton transfer from the co-former to ibuprofen lysine [18]. A strong band, in the range of $1610-1550 \mathrm{~cm}^{-1}$ is observed in the IR spectra of aryl carboxylate salts and can be attributed to the asymmetric vibration. The IR spectrum did not reveal any band in this region. It was concluded that A5 and B8 was a co-crystal rather than a salt.

\section{Differential scanning calorimetry (DSC)}

The DSC curves of ibuprofen lysine and the co-formers are shown in fig. 5, 6 and 7.

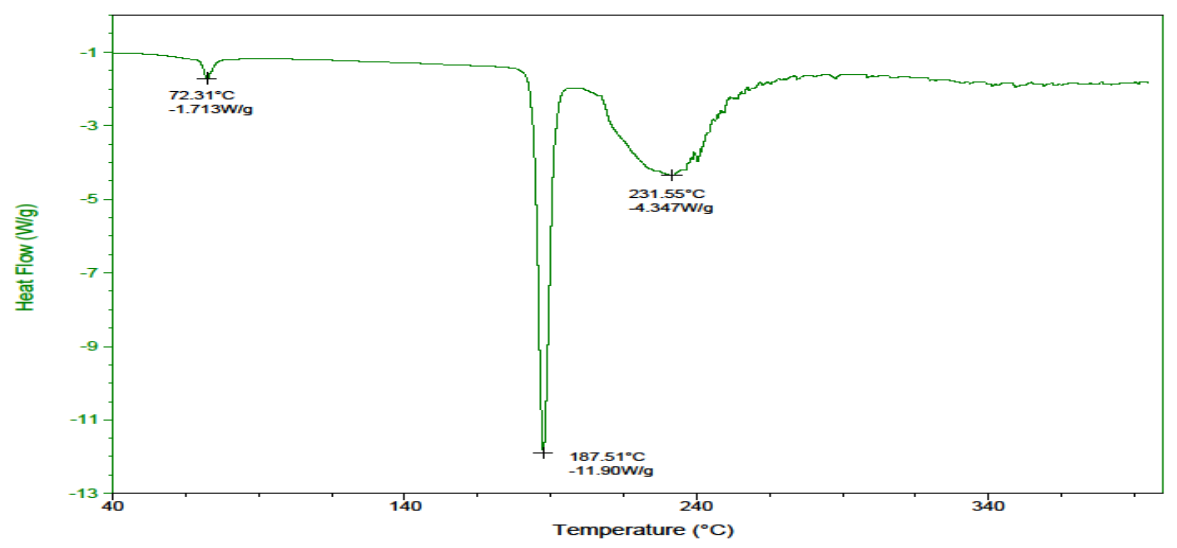

Fig. 5: DSC thermogram of ibuprofen lysine

Ibuprofen lysine was subjected to thermal screening by DSC. (fig. 5) The DSC thermogram revealed a small endothermic peak at $72.35^{\circ} \mathrm{C}$, the sharp endothermic peak at $187.51{ }^{\circ} \mathrm{C}$ and a broad endotherm at $231.5^{\circ} \mathrm{C}$. The first peak may be attributed to a small mass loss from the API sample. The mass loss was associated to vaporization of water from the API sample. The second sharp endotherm indicated a melting point of ibuprofen. The broad endotherm was attributed to the melting and decomposition of lysine.

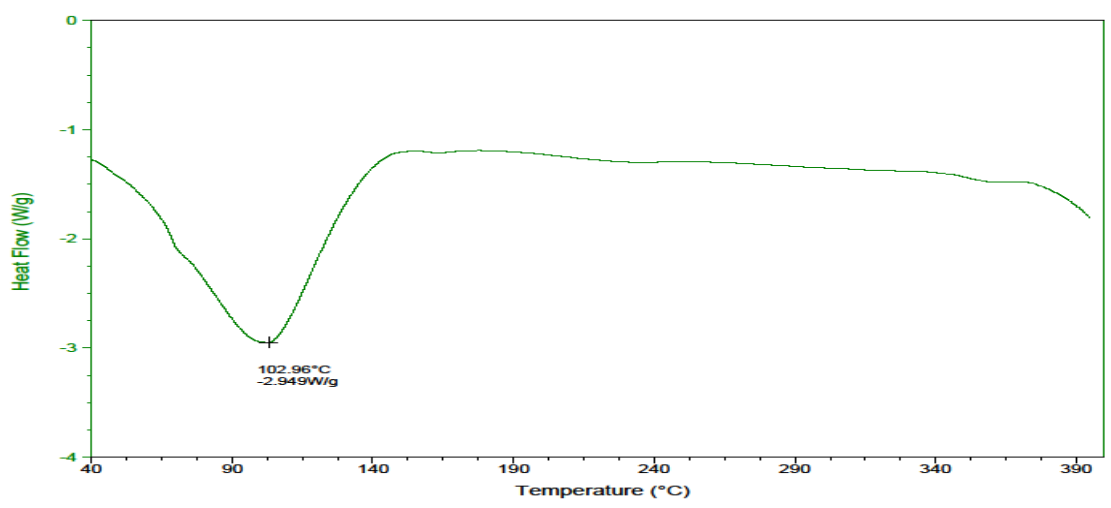

Fig. 6: DSC thermogram for PK-25 


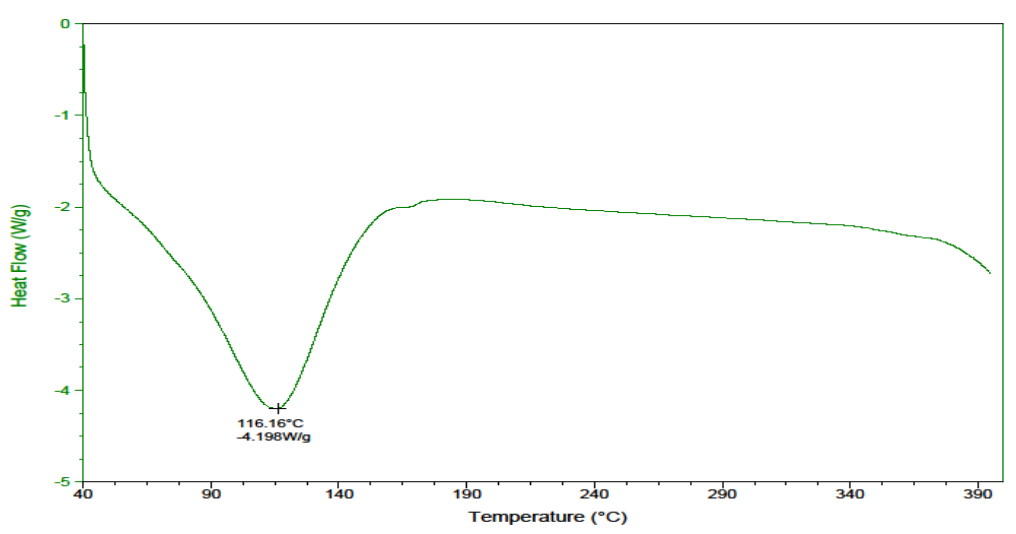

Fig. 7: DSC thermogram for PK-30, DSC thermo grams of the co-formers revealed typical polymeric behaviour. (fig. 6 and 7)

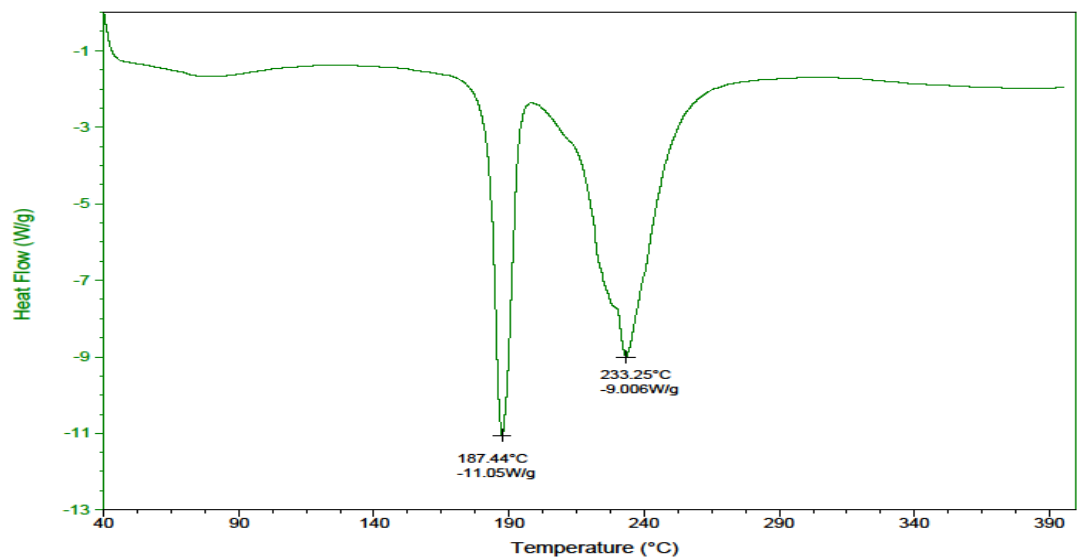

Fig. 8: DSC thermogram of co-crystal A5

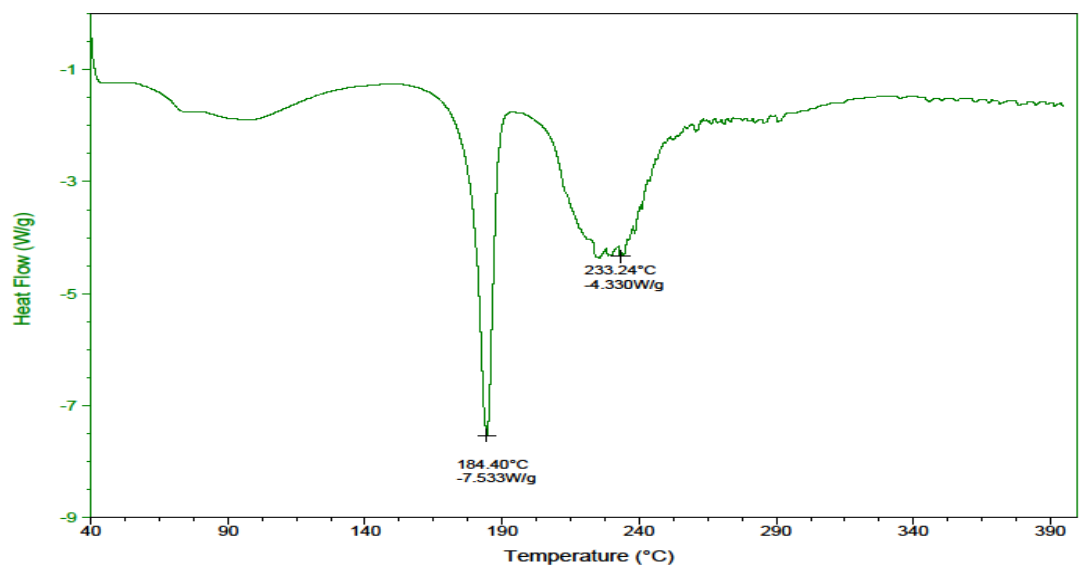

Fig. 9: DSC thermogram of co-crystal B8

The melting point of ibuprofen co-crystal was lower or different than the melting point of ibuprofen or the co-former [18]. However, the melting point of the co-crystal was similar to the melting point of ibuprofen lysine in our study. The DSC curves of the co-crystal A5 and B8 (fig. 8 and 9 respectively) revealed an endothermic peak at $187{ }^{\circ} \mathrm{C}$ and $184{ }^{\circ} \mathrm{C}$ respectively. It indicated the presence of ibuprofen lysine in the co-crystals. The endotherm, at $72.35{ }^{\circ} \mathrm{C}$ for ibuprofen lysine, was absent in the thermogram of the co-crystals.

The melting point of nicotinamide-2-chloro-4-nitrobenzoic acid $\mathrm{c} 0$ crystal was higher than the individual components [8]. The higher melting point indicated higher stability of the co-crystal. The DSC curve of A5 (fig. 8) revealed an intense endothermic peak with a small shoulder at $233{ }^{\circ} \mathrm{C}$. The DSC curve of B8 (fig. 9) revealed a broad endotherm at $233{ }^{\circ} \mathrm{C}$. These peaks were different in appearance from that of ibuprofen lysine. These peaks indicated the formation of $\mathrm{H}$ bonds and the possibility of crystal lattice arrangement between ibuprofen lysine and the co-formers to some extent. It was predicted that the crystal lattice arrangement was not completely formed. The inability of completion of crystal lattice rearrangement was due to inadequate drug: co-former stoichiometric ratio.

\section{PXRD study}

The formation of co-crystals was confirmed from PXRD study since the diffraction lines of the co-crystals A5 and B8 were considerably different from the peak positions of ibuprofen lysine and the co- 
former. Ibuprofen lysine displayed the prominent peaks at $2^{\circ} \theta=10.5$, $11.19,12.17,12.95,15.30,16.60$. 18.91. (fig. 10) Our results are corroborated by Renato et al., who have reported the characteristic peaks of ibuprofen at $2^{\circ} \theta=12.24,16.3$ [19].

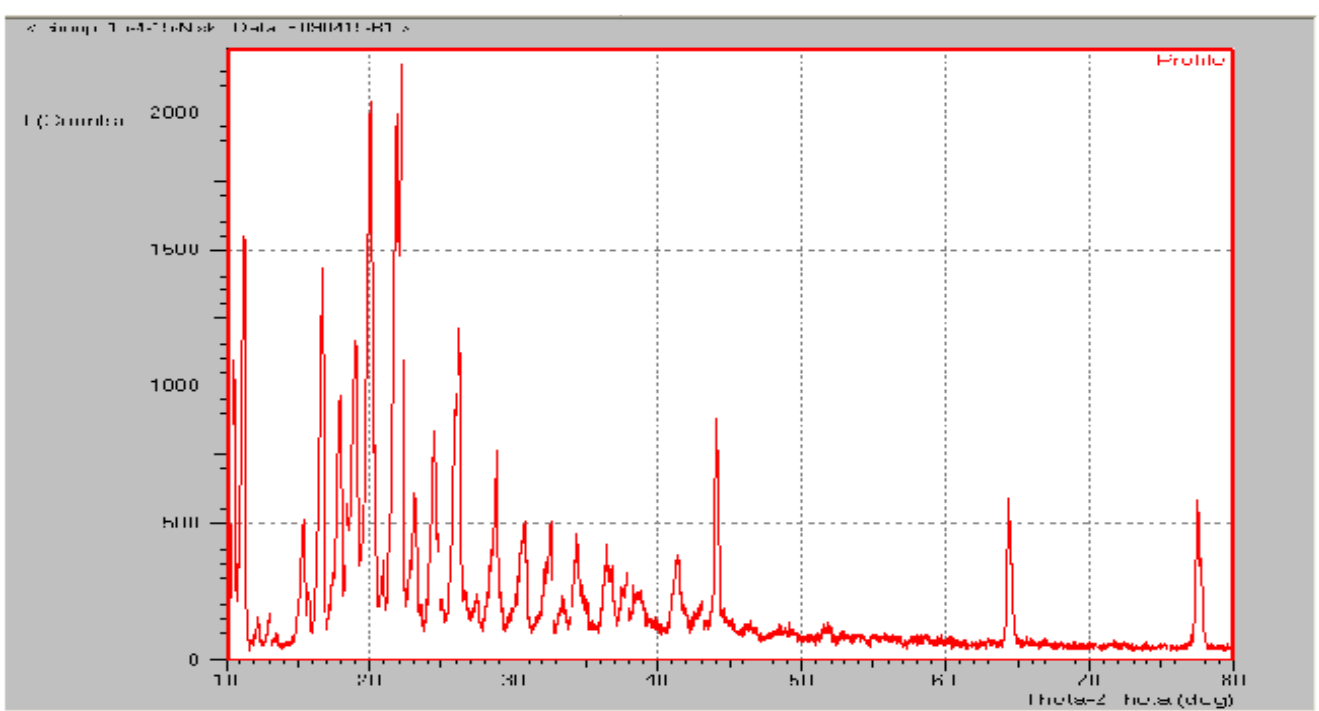

Fig. 10: PXRD patterns of ibuprofen lysine, the PXRD spectra of PK-25 and PK-30 (fig. 11 and 12) revealed diffuse spectra, characteristic of polymeric nature

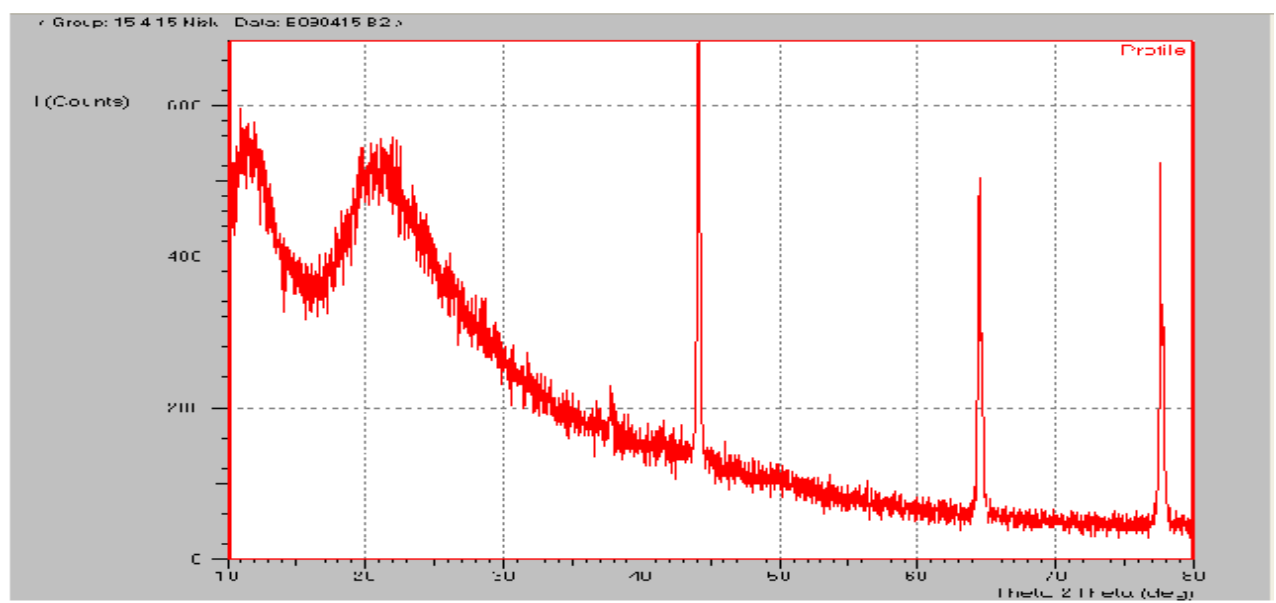

Fig. 11: PXRD patterns of PK-25

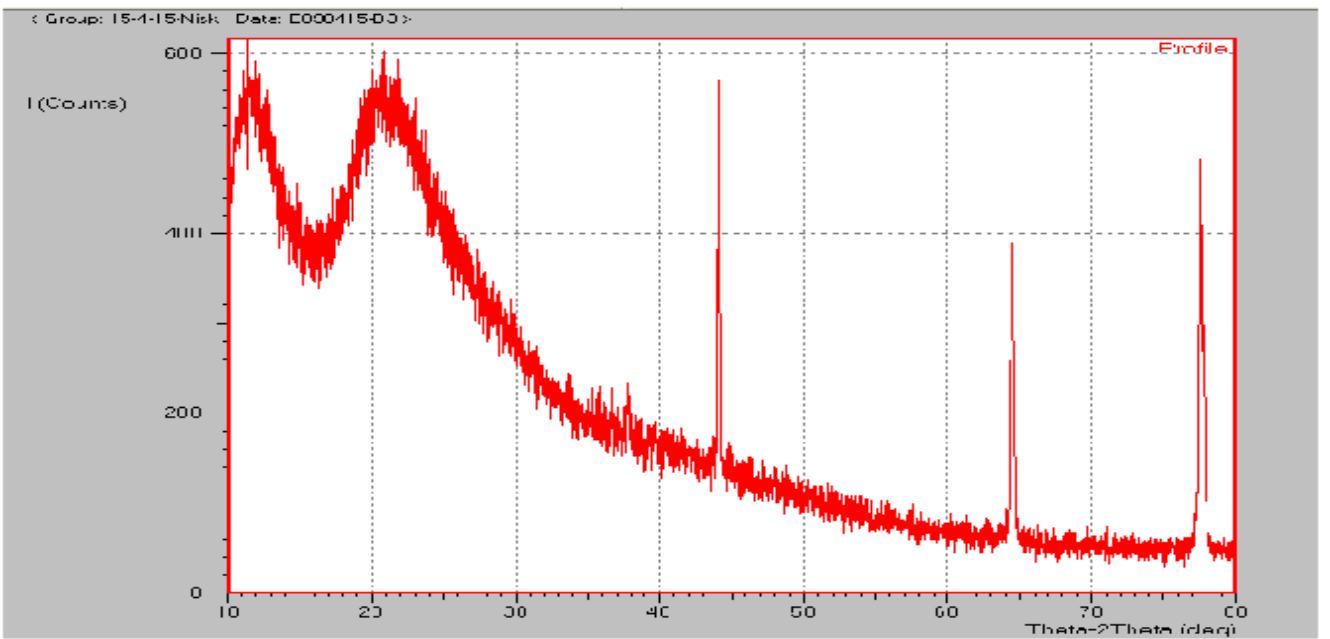

Fig. 12: PXRD patterns of PK-30 
Renato et al. observed the difference between the XRD patterns of ibuprofen-nicotinamide co-crystals and ibuprofen/nicotinamide. The diffraction lines of the co-crystals A5 and B8 were considerably different from the peak positions of ibuprofen and the co-former [19]. (fig. 13 and 14) A prominent peak, at $2^{\circ} \theta=10.86$ and 10.58 , along with the appearance of numerous peaks, confirmed the formation of new crystalline structure. The peaks indicated the crystal lattice arrangement between ibuprofen and the co-formers to some extent. The inability of completion of crystal lattice rearrangement was due to inadequate drug: co-former stoichiometric ratio.

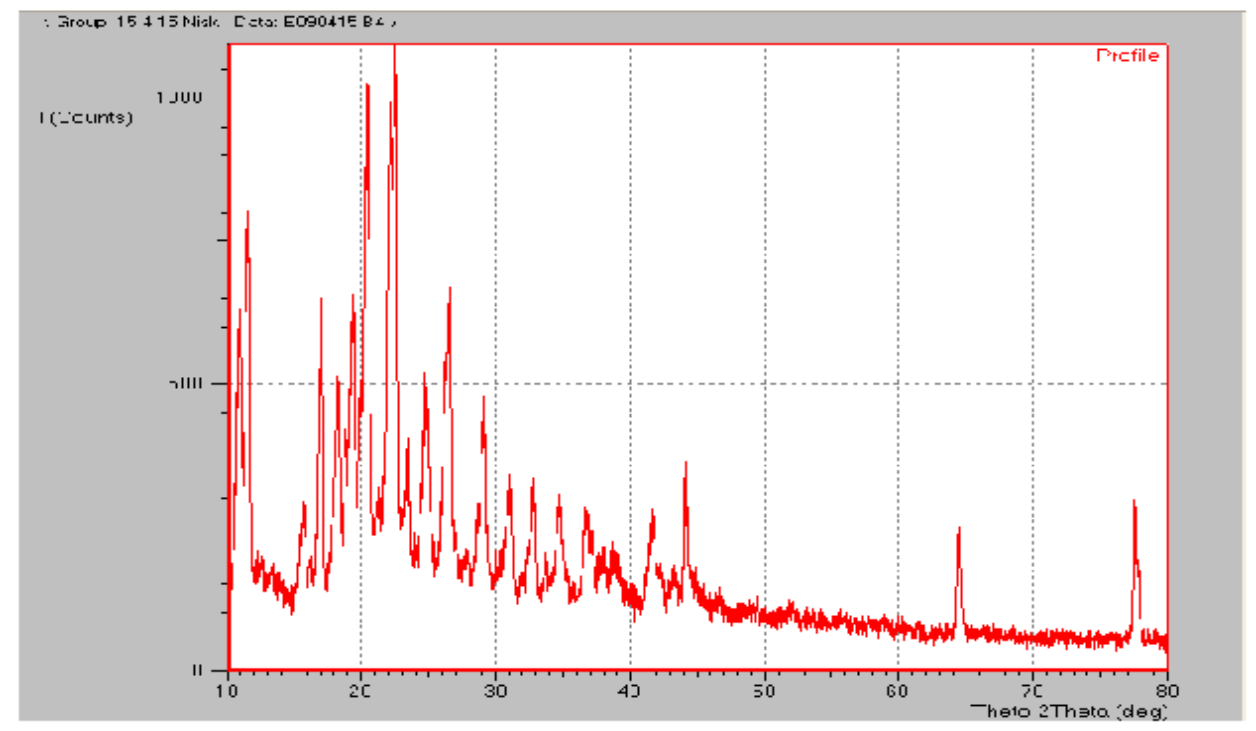

Fig. 13: PXRD patterns of co-crystal A5

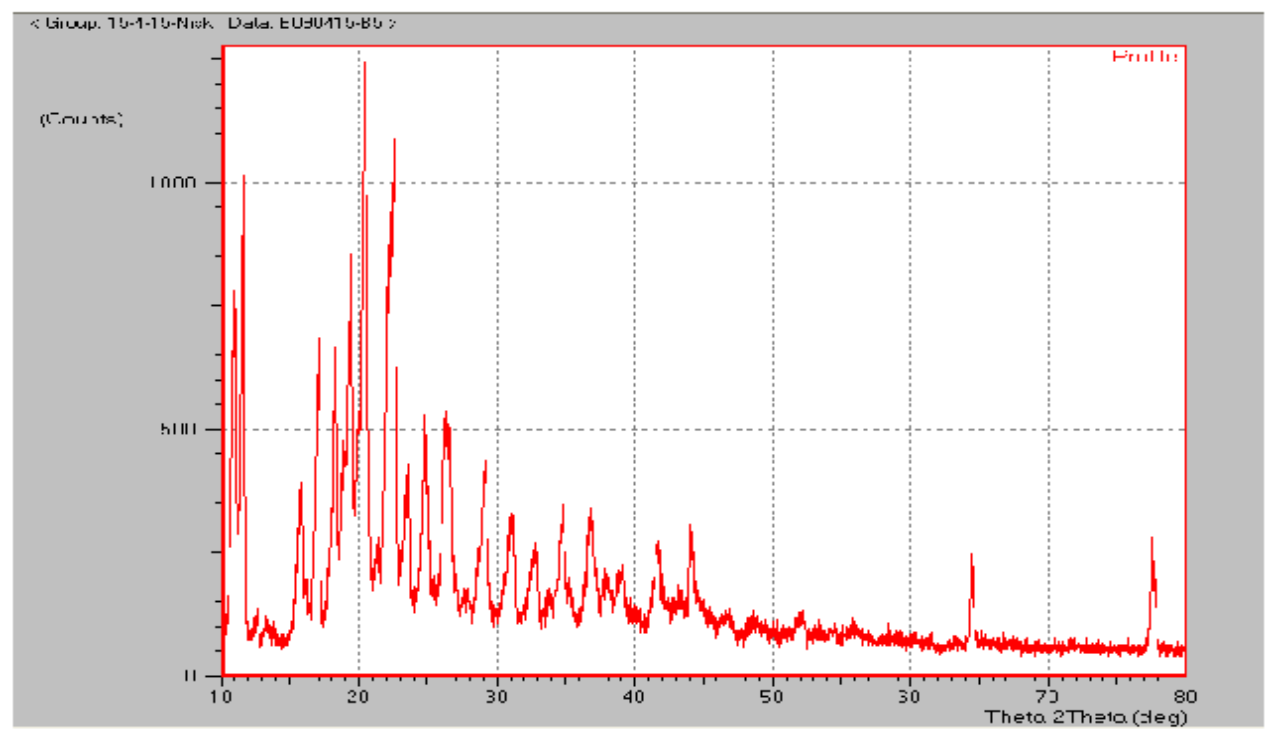

Fig. 14: PXRD patterns co-crystal B8

\section{Morphology study}

Morphologies of ibuprofen lysine drug substance, the coformers, and the co-crystal particles were investigated. Ibuprofen lysine crystals appeared as irregular crystals agglomerated in bundles (fig. 15), whereas the co-formers appeared as transparent, almost rectangular particles. (fig. 16 and 17) Microscopic analysis of solids A5 and B8 were consistent with DSC and FTIR study. The characteristic appearance of ibuprofen lysine and Polyvinylpyrrolidone disappeared in B8 solid. It appeared as irregular solid aggregates making it impossible to differentiate between cocrystal components. (fig. 18) The solid A5 was rectangular, transparent, and opaque (fig. 19).

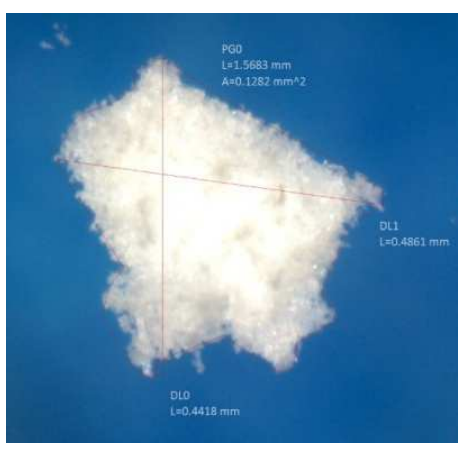

Fig. 15: ibuprofen lysine 


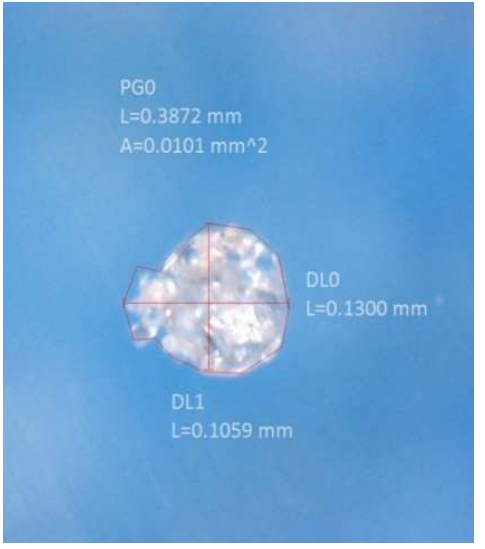

Fig. 16: PK 25

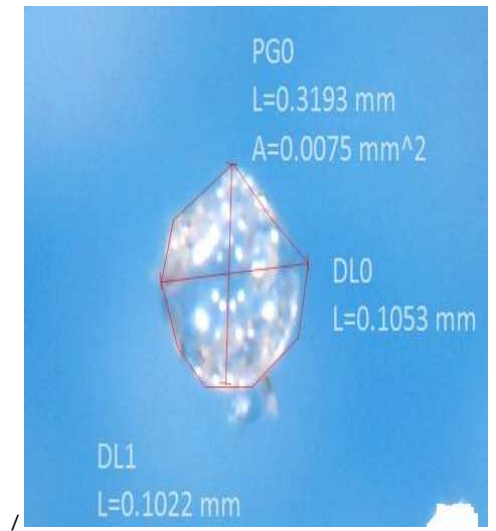

Fig. 17: PK 30

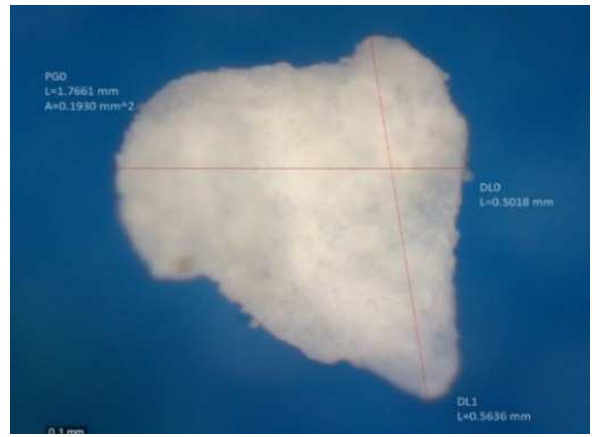

Fig. 18: Co-crystal B8

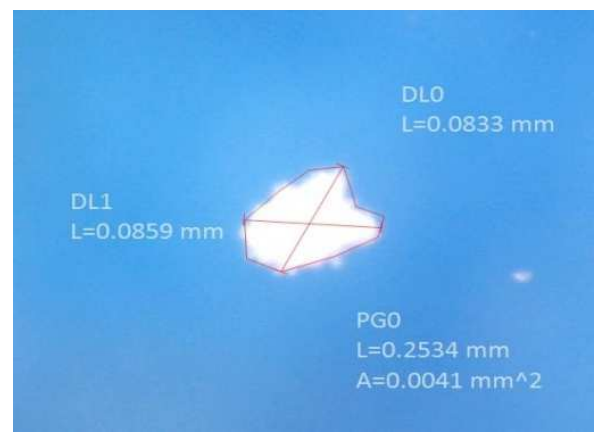

Fig. 19: Co-crystal A5

Evaluation of tablet formulations of co-crystals of ibuprofen lysine

The tablets were round, white, smooth in appearance. Tablets $\mathrm{T} 1$, T2, T3 complied with tablet thickness, diameter, weight variation, hardness, friability (table 9)

Table 9: Characterization of tablet formulations

\begin{tabular}{|c|c|c|c|c|}
\hline S. No. & Parameter & T1 tablets & T2 tablets & T3 tablets \\
\hline 1 & Average weight (g) & $0.3269 \pm 0.014$ & $0.3107 \pm 0.009$ & $0.3418 \pm 0.006$ \\
\hline 2 & Hardness (kg/cm2) & $4.5 \pm 0.018$ & $4.6 \pm 0.012$ & $4.6 \pm 0.015$ \\
\hline 3 & Disintegration time (min) & 11.7 & 9.89 & 17.85 \\
\hline 4 & Friability (\% weight/weight) & 1.1 & 0.6 & 0.61 \\
\hline \multirow[t]{2}{*}{5} & Dimension Thickness $(\mathrm{mm})$ & $0.4833 \pm 0.0057$ & $0.4766 \pm 0.0057$ & $0.4833 \pm 0.0057$ \\
\hline & Diameter (mm) & $0.8733 \pm 0.0057$ & $0.08833 \pm 0.0057$ & $0.088 \pm 0.01$ \\
\hline
\end{tabular}

Each observation is an average of three experiments $(n=3) \pm S D$

The results revealed that the dissolution rate of T2 tablets (cocrystal A5) was lower than the dissolution rate of T1 tablets (IL alone). (table 10) It was attributed to the method of preparation of the co-crystals. The co-crystal A5 was prepared by LAG in two steps 1) addition of solvent to the API: co-former mixture and 2) mechanical shaking of the mixture. It is proposed that the co-former has formed the co-crystals. In addition, Polyvinylpyrrolidone, the coformer, formed a viscous gel upon contact with water. This has promoted retardation of the drug release rate, as observed in T2 tablets. SE method, employed for preparing the co-crystal B8, consists of 1) addition of solvent to the API: co-former mixture and 2) evaporation of the solvent. The extent of interaction between IL and Polyvinylpyrrolidone, the co-former, was higher in SE method. Hence the co-former was unable to form the viscous gel. This has lead to higher dissolution rate of T3 tablets than the dissolution rate of T1 tablets (IL alone) (table 10).

Table 10: In vitro drug release profile of T1, T2 and T3 tablets

\begin{tabular}{lllll}
\hline S. No. & Time (min) & \% Drug release & T2 tablets & T3 tablets \\
\cline { 2 - 5 } & & T1 tablets & $13.91 \pm 3.79$ & $40.39 \pm 16.07$ \\
\hline 1 & 30 & $29.69 \pm 1.35$ & $29.52 \pm 6.49$ & $96.14 \pm 13.98$ \\
2 & 60 & $55.90 \pm 0.97$ & $40.73 \pm 9.67$ & $112.94 \pm 14.02$ \\
4 & 90 & $74.61 \pm 3.51$ & $47.90 \pm 3.14$ & $113.57 \pm 13.89$ \\
5 & 120 & $77.35 \pm 3.77$ & $56.81 \pm 5.86$ & $114.23 \pm 6.496$ \\
6 & 180 & $80.40 \pm 2.99$ & $60.38 \pm 6.19$ & -- \\
7 & 240 & $81.93 \pm 4.89$ & $59.28 \pm 4.62$ & -- \\
8 & 300 & $77.34 \pm 2.19$ & $59.24 \pm 3.07$ & \\
\hline
\end{tabular}

Each observation is an average of three experiments $(\mathrm{n}=3) \pm \mathrm{SD}$ 


\section{In vivo study of tablet formulations of co-crystals of ibuprofen} lysine

The effect of ibuprofen formulations on reaction time in hot plate method are presented in table 11 . The mean baseline observations were $2.043,1.398,1.668,1.900$ and $2.138 \mathrm{~min}$ respectively for Group I, II, III, IV and V with the corresponding coefficient of variation $19.69 \%, 12.31 \%, 8.85 \%, 5.45 \%$ and $25.13 \%$. At 45 min of the study, the T2 tablet formulation increased the reaction time of heat sensation to $19.66 \%$ in Group I. At 15 and 45 min of study, the T3 tablet formulation increased the reaction time of heat sensation to 46.70 and $57.93 \%$, respectively. At 15 and $45 \mathrm{~min}$ of study, the Brufen ${ }^{\circledR}$ tablet formulation increased the reaction time of heat sensation to 0.94 and $29.50 \%$, respectively. At 60 and $120 \mathrm{~min}$ of study, the reaction time of heat sensation was higher for $\mathrm{T} 2$ and $\mathrm{T} 3$ tablet formulations than $\mathrm{T} 1$ tablet formulation.

Table 11: Analgesic activity of tablet formulations

\begin{tabular}{|c|c|c|c|c|c|}
\hline \multirow[t]{2}{*}{ Time (min) } & \multicolumn{5}{|l|}{ Reaction time (min) } \\
\hline & Group I & Group II & Group II & Group IV & Group V \\
\hline 0 & $2.043 \pm 0.1969$ & $1.398 \pm 0.1231$ & $1.668 \pm 0.08845$ & $1.900 \pm 0.05447$ & $2.138 \pm 0.2513$ \\
\hline 15 & $2.498 \pm 0.07319$ & $2.623 \pm 0.1584 \mathrm{a}^{* * *} \mathrm{~d}^{* * *} \mathrm{e}^{* * *} \mathrm{f}^{* * *}$ & $2.403 \pm 0.2652$ & $1.918 \pm 0.08645 \mathrm{c}^{*} \mathrm{~d}^{*} \mathrm{e}^{* * *} \mathrm{f}^{* * *}$ & $2.718 \pm 0.1726$ \\
\hline 30 & $1.340 \pm 0.02614 \mathrm{e}^{*} \mathrm{f}^{*}$ & $2.180 \pm 0.1526 \mathrm{a}^{* *} \mathrm{c}^{* * *} \mathrm{e}^{* * *} \mathrm{f}^{* * *}$ & $2.660 \pm 0.1411$ & $2.663 \pm 0.1855 \mathrm{a}^{*} \mathrm{~b}^{*} \mathrm{e}^{*} \mathrm{f}^{*}$ & $2.855 \pm 0.1753$ \\
\hline 45 & $2.543 \pm 0.1299$ & $3.323 \pm 0.06928 a^{* * *} b^{* *} c^{* * *} f^{*}$ & $3.010 \pm 0.3844 \mathrm{a}^{*}$ & $2.695 \pm 0.1830 a^{* *} b^{*} e^{*} f^{*}$ & $2.663 \pm 0.1581$ \\
\hline 60 & $3.328 \pm 0.8417 c^{* *}$ & $3.698 \pm 0.1903 \mathrm{a}^{* * *} \mathrm{~b}^{* * *} \mathrm{c}^{* * *}$ & $3.268 \pm 0.3166 \mathrm{a}^{* *}$ & $3.395 \pm 0.1696 a^{* * *} b^{* * *} c^{*} d^{*}$ & $2.798 \pm 0.1993$ \\
\hline 120 & $3.238 \pm 0.3677 c^{*}$ & $3.945 \pm 0.08703 a^{* * *} b^{* * *} c^{* * *} d^{*}$ & $3.160 \pm 0.4517 \mathrm{a}^{*}$ & $3.350 \pm 0.2089 a^{* * *} b^{* * *} c^{*} d^{*}$ & $2.065 \pm 0.1990$ \\
\hline
\end{tabular}

Where $\mathrm{a}=0 \mathrm{~min}, \mathrm{~b}=15 \mathrm{~min}, \mathrm{c}=30 \mathrm{~min}, \mathrm{~d}=45 \mathrm{~min}, \mathrm{e}=60 \mathrm{~min}, \mathrm{f}=120 \mathrm{~min}$, Each observation is an average of three experiments $(\mathrm{n}=6) \pm \mathrm{SEM}$

The mean peak effect remained above $3 \mathrm{~s}$ between $60-120 \mathrm{~min}$ in group I, between $45-120 \mathrm{~min}$ in group II, between $45-60 \mathrm{~min}$ in group III, between $60-120 \mathrm{~min}$ in group IV and at $120 \mathrm{~min}$ in group $\mathrm{V}$. The analgesic effect, in the increasing order, was demonstrated as Group II $>$ Group IV and I $>$ Group III $>$ Group V. The co-crystal of ibuprofen lysine B8 demonstrated significant analgesic activity.

\section{CONCLUSION}

The formation of the co-crystals in between ibuprofen lysine (IL) and polyvinylpyrrolidone K-25 (PK 25)/polyvinylpyrrolidone K-30 (PK 30) was confirmed. It indicated an improvement in aqueous solubility of IL by co-crystallization of IL with PK 25 and PK 30. It demonstrated that a tablet of co-crystal with sufficient hardness, necessary for manufacturing and distribution, can be formulated. The co-crystals of ibuprofen lysine demonstrated significant analgesic activity than the marketed tablet. The present study illustrates the utility of PK 25 and PK 30 as safe and promising co-crystal formers.

\section{FUNDING}

Nil

\section{AUTHORS CONTRIBUTIONS}

All the authors have contributed equally.

\section{CONFLICT OF INTERESTS}

Declared none

\section{REFERENCES}

1. Gruber P. Solubilized ibuprofen. EP1863460A2; 2013. Available from: www.google.com.ar/patents/ [Last accessed on 15 Oct 2019]

2. Nerurkar J, Beach JW, Park MO, Jun HW. Solubility of ( \pm )ibuprofen and S (+)-ibuprofen in the presence of cosolvents and cyclodextrins. Pharm Dev Techonol 2005;10:413-21.

3. Zalte AG, Darekar AB, Gondkar SB, Saudagar RB. Preparation and characterization of ibuprofen co-crystals by using the solvent grinding method. World J Pharm Res 2014;3:1392-402.

4. Trask AV, Sam Motherwell WD, Jones W. Physical stability enhancement of theophylline via cocrystallization. Int J Pharm 2006;320:114-23.

5. Desiraju GR. Crystal and co-crystal. Cryst Eng Comm 2003;5:466-7.

6. Aakeroy CB, Desper J, Helfrich BA. Heteromeric intermolecular interactions as synthetic tools for the formation of binary cocrystals. Cryst Eng Comm 2004;6:19-24.

7. Karki S, Friscic T, Fabian L, Laity PR, Day GM, Jones W. Improving mechanical properties of crystalline solids by cocrystal formation: new compressible forms of paracetamol. Adv Mater 2009;21:3905-9.

8. Lemmerer A, Esterhuyesn C, Bernstein J. Synthesis, characterization and molecular modeling of a pharmaceutical co-crystal: (2-chloro-4-Nirtrobezoic Acid): (nicotinamide). J Pharm Sci 2010;99:4054-71.

9. Bohler V. Kollidon polyvinylpyrrolidone for the pharmaceutical industry. BASF The Chemical Industry. 4th ed. Ludwigshafen, Germany: BASF; 1998.

10. Rowe RC, Sheskey PJ, Owen SC. editors. Handbook of pharmaceutical excipients. 5th ed. London, UK: Pharmaceutical Press; 2005.

11. Merck MJ, O'Neil M, Smith A, Heckelman PE, Budavari S. editors. The Merck Index: An Encyclopedia of chemicals, drugs, and biologicals. 13th ed. New Jersey: Merck Research Laboratories Division of MERCK and CO; 2001.

12. Savant DA. editor. The Pharmaceutical Science, Pharma Pathway Pure Applied Pharmacy. 1st ed. Pune: Nirali Prakashan; 2016.

13. Government of India Ministry of Health and Family Welfare, editor. In Indian Pharmacopoeia. Vol. I. and Vol. II. 6th ed. Ghaziabad: Indian Pharmacopoeia Commission; 2010.

14. University of the Sciences in Philadelphia, editor. Remington: The Science and Practice of Pharmacy. Vol. I. 21 $1^{\text {st }}$ ed. Philadelphia: Lippincott Williams and Wilkins; 2005.

15. United States Pharmacopoeia, editor. USP/NF 2004 (USP 27/NF22). Maryland, USA: United States Pharmacopoeial Convention; 2004.

16. Pharmaceuticals and Medical Devices Agency. editor. The Japanese Pharmacopoeia. 16th ed. Tokyo: Pharmaceuticals and Medical Devices Agency; 2011.

17. Sharma HL, Sharma KK. editors. Principles of Pharmacology. 1st ed. New Delhi: Paras Medical Publishers; 2007.

18. Chow SF, Chen M, Shi L, Chow AH, Sun CC. Simultaneously improving the mechanical properties, dissolution performance, and hygroscopicity of ibuprofen and flurbiprofen by cocrystallization with nicotinamide. Pharm Res 2012;29:1854-65.

19. Soares FLF, Carneiro RL. Green synthesis of ibuprofennicotinamide cocrystals and in-line evaluation by Raman spectroscopy. Cryst Growth Des 2013;13:1510-7.

20. Alshahateet SF. Synthesis and X-ray crystallographic analysis of pharmaceutical model Rac-ibuprofen cocrystal. J Chem Crystallogr 2011;41:276-9.

21. Jagadeesh Babu N, Shreeniwas LR, Nangia A. Amide- N-Oxide heterosynthon and amide dimer homosynthon in cocrystals of carboxamide drugs and pyridine N-oxides. Mol Pharmaceutics 2007;4:417-34.

22. Acids and bases: molecular structure and acidity. Available from: http://www.chem.ucla.edu/ harding/tutorials/acids_and_bases/ mol_str.pdf. [Last accessed on 15 Oct 2019]

23. Hickey MB, Peterson ML, Scoppettuolo LA, Morrisette SL, Vetter A, Guzman $\mathrm{H}$, et al. Performance comparison of a cocrystal of carbamazepine with marketed product. Eur J Pharm Biopharm 2007;67:112-9. 